\title{
Mutations in CDKN2C (p18) and CDKN2D (p19) may cause sporadic parathyroid adenoma
}

\section{Dear Editor}

Hyperparathyroidism (HPT) can arise from germline mutation of multiple endocrine neoplasia type 1 (MEN1), CASR, or HRPT (HRPT1; Marx 2011). Recent studies also suggested that germline mutation of several cyclin-dependent kinase inhibitors (CDKIs) is an uncommon cause of HPT (Pellegata et al. 2006, Agarwal et al. 2009). A gene that predisposes to tumor via germline mutation may also predispose to similar tumor by somatic mutation; in fact, the MEN1 gene is mutated in about 30\% of sporadic parathyroid tumors (Marx 2011). Screening a small number of sporadic parathyroid tumors by others, using whole exome sequencing analysis, did not show any CDKI gene mutation (Cromer et al. 2012, Newey et al. 2012). In a recent study, all seven CDKI genes were sequenced in 81 sporadic parathyroid adenomas. There were five novel DNA missense changes in $p 15, p 18$, and $p 21$. Three to four of these were also in the germline, and none of the five were unequivocally a pathological mutation, such as a truncation change (Costa-Guda et al. 2013). We further evaluated whether some cases of sporadic parathyroid adenoma are caused by somatic mutation in CDKI genes.

We evaluated tumors from 42 patients, who underwent parathyroid surgery at NIH. Each patient had a postoperative diagnosis of sporadic parathyroid adenoma. Each patient gave written informed consent to a protocol that had been approved by the NIDDK Institutional Review Board. See Supplementary Materials and methods, see section on supplementary data given at the end of this article.

In 42 sporadic parathyroid adenomas, we found 15 SNPS plus one deletion and one insertion among the seven CDKI genes. With the exception of two SNPs and the indels, the remaining SNPs were previously reported (Supplementary Table 1, see section on supplementary data given at the end of this article). Four unreported variations were found in $C D K N 2 C$ and $C D K N 2 D$. CDKN2C encodes p18, a known tumor suppressor (Solomon et al.
2008, van Veelen et al. 2009). CDKN2D encodes p19, which is closely related to p18 but not previously considered as a tumor suppressor.

One parathyroid tumor showed a deletion in the p18 gene and one showed an insertion in p18; neither change was found in the patient's germline. In the first (p18F71Ter), a 25-nucleotide deletion at c.1427_1454del causes a stop codon at Phe 71. In the second (p18V118fs*6), a two-nucleotide insertion c.1567_1568insGG causes a frameshift, followed by new sequence GWSSWWstop, also predicting a shortened protein. The chromatograms in Fig. 1A and B show overlapping WT and mutant sequences, indicating heterozygosity or normal admixture. Western blots show stable expression of transfected WT p18 (Fig. 2A, lane 2) and no detectable expression of either changed $p 18$ (Fig. 2A, lanes 3 and 5). Transfection efficiency was checked with NPT-II and did not vary significantly between lanes (not shown).

The p19 A164T change in two parathyroids is absent in the germline of one patient but present in the germline of the other; the p19 V123A change is absent in the patient's germline (Supplementary Fig. 1A and B, see section on supplementary data given at the end of this article). Transient transfection experiments demonstrate that both p19 changes are stably expressed at levels comparable to WT (Fig. 2B).

Each of the seven CDKIs is conserved and consists of four or five ankyrin repeat motifs (Li et al. 2006). Missense mutations, thought to contribute to tumorigenesis by INK4 CDKI proteins, occur throughout the first four ankyrin repeats; they disrupt interactions with CDKs or with other proteins (Baumgartner et al. 1998, Li et al. 2006).

Even if expressed in vivo, neither of the observed p18 truncation mutants is likely to be active. The 70 amino acid p18 F71Ter lacks two of the four ankyrin repeats required for known interactions with CDK4

Published by Bioscientifica Ltd. 
A

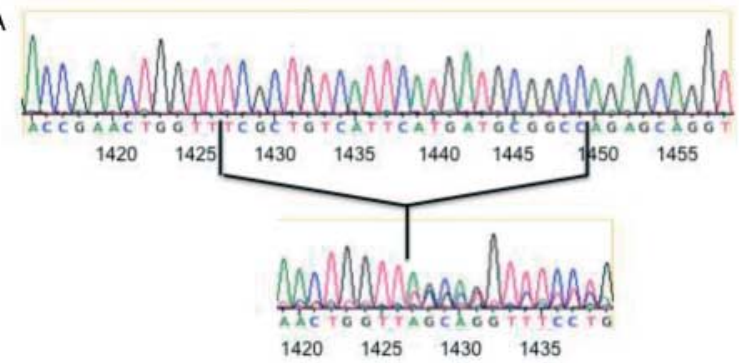

B

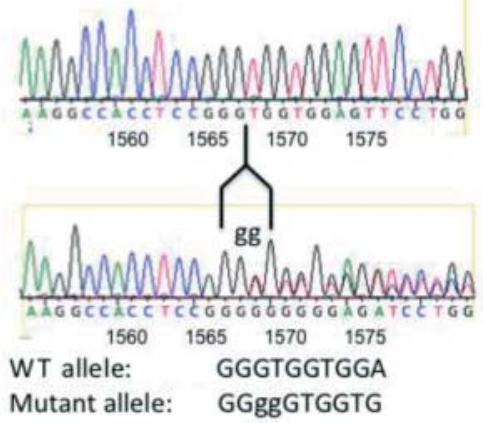

Figure 1

Sequencing of CDKN2C exon 2. (A) Upper chromatogram shows normal germline CDKN2C exon 2 nucleotide sequence and the lower chromatogram shows DNA sequence from parathyroid tumor with the c.1427-1454 deletion. The perpendicular line pointing to the bottom trace indicates the location of this deletion. The upper trace shows the germline sequence with the location of deleted nucleotides bounded by the black vertical lines. Overlapping sequence is also present at upstream sites (not shown). (B) Upper chromatogram shows normal germline sequence and the lower chromatogram shows the tumor DNA sequence harboring the insertion at c.1567. The GG indicates the location of the insertion of two guanosines. Heterozygosity is suggested by overlapping base calls. The text below compares the nucleotide sequence of WT allele with the mutant allele containing the insertion.

(Guo et al. 2009). The p118V118 fs* (Guo 2009) omits the conserved V118 and truncates the protein with GWSSW prior to the fifth ankyrin repeat. The mutated frameshift residues do not align with the ankyrin repeat consensus sequence. Furthermore, the truncated p18 protein containing residues 1-137 and containing the first four $\mathrm{N}$-terminal ankyrin repeats would be one tenth or less as active as the WT (Guo et al. 2009). In sum, both the p18 indels are probably loss-of-function drivers of parathyroid tumorigenesis. Each predicts a severely truncated protein, modeling of the ankyrin repeats predict impaired interaction with CDKs, and neither mutant protein was expressed in vitro. Thus, the evidence for loss of function of p18 is particularly strong. This also supports a role of p18 in parathyroid tumorigenesis, as p18 and most other members of the CDKI family participate in tumorigenesis via loss of function (Li et al. 2011).
The C-terminal five amino acids of p19 are not identical among mammals and are poorly conserved in animals (Supplementary Fig. 1A); these amino acids are predicted not to make contact with the CDKs, and thus the p19A164T mutation is unlikely to affect p19 function in the cell cycle. The p19V123A is in the fourth ankyrin repeat (Supplementary Fig. 1B) and is a conservative amino acid change found in the homologous p16 and p15. Structural alignment shows that p19 and p16 closely overlap in this region and in the remainder of the first four ankyrin repeats (Supplementary Fig. 1C). In other species, alanine is easily accommodated in the region otherwise occupied by WT valine (Supplementary Fig. 1B). Lastly, other amino acid changes in the homologous position in p16 are benign (Pavletich 1999). Lacking strong evidence for loss of function, we judged both p19A164T and p19V123A as polymorphisms that were unlikely to drive parathyroid tumorigenesis. Still, the lack of either of these p19 missense changes in normal controls indicates that either might be tumorigenic. Later studies might uncover deleterious functional consequences of either of these missense changes in $p 19$.

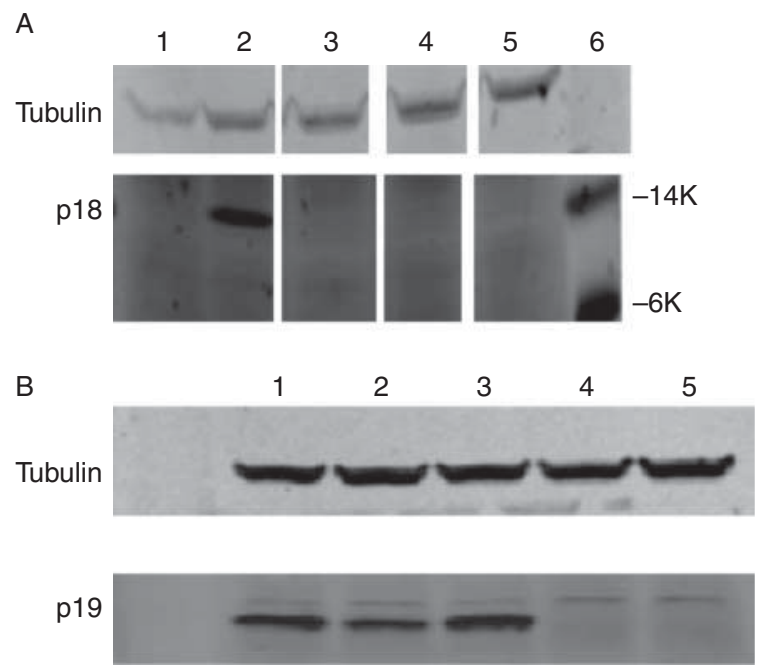

Figure 2

Western blot of the expression of transfected p18 and p19 (WT and two variants of each). Transfection efficiency was similar for all lanes, judged by levels of NPT-II from the vector (not shown). (A) Western blot of p18, p18F71Ter, and p18V118fs*6 isolated from transiently transfected HEK 293 cells. Lane 1, no vector; lane 2, p18; lane 3, p18V118fs*6 (p18c.1567_1568insGG); lane 4, vector; lane 5, p18F71Ter (p18 c.147_1454del); and lane 6, molecular weight markers. Tubulin is the loading control. (B) Western blot of $\mathrm{p} 19$ and missense mutants. Lane 1, p19; lane 2, p19V123A; lane 3, p19A164T; lane 4, vector; and lane 5, no vector. Tubulin is the loading control.

Published by Bioscientifica Ltd. 
We have provided strong evidence for somatic inactivation of $p 18$. The truncating mutations observed in $p 18$ also give conceptual support for the pathogenicity of some of the previously reported missense mutations.

\section{Thomas Gluick ${ }^{1}$ \\ Ziqiang Yuan ${ }^{2}$ \\ Steven K Libutti ${ }^{2}$ \\ Stephen J Marx ${ }^{1}$}

${ }^{1}$ Genetics and Endocrinology Section, Metabolic Diseases Branch, National Institute of Diabetes and Digestive and Kidney Diseases, National Institutes of Health, Bld 10, Room 9C-103, 10 Center Drive, Bethesda, Maryland, 20892, USA

${ }^{2}$ Departments of Surgery and Genetics, Albert Einstein College of Medicine, 1300 Morris Park Avenue, Bronx, New York, 10461, USA

(Correspondence should be addressed to S J Marx); email: marxs@mail.nih.gov

\section{Supplementary data}

This is linked to the online version of the paper at http://dx.doi.org/10.1530/ ERC-13-0445.

\section{Declaration of interest}

The authors declare that there is no conflict of interest that could be perceived as prejudicing the impartiality of the research reported.

\section{Funding}

This study was supported by the intramural NIH programs of NIDDK and $\mathrm{NCl}$.

\section{Acknowledgements}

T Gluick thanks Kazuhio Horiguchi and former colleagues in the Marx laboratory for support and discussions, Sunita Agarwal for PCR primers and for helpful suggestions, and Asha Adem for preparation of the parathyroid DNA samples. The authors dedicate this paper to late Dr Carmen Mateo.

\section{References}

Agarwal SK, Mateo CM \& Marx SJ 2009 Rare germline mutations in cyclindependent kinase inhibitor genes in multiple endocrine neoplasia type 1 and related states. Journal of Clinical Endocrinology and Metabolism 94 1826-1834. (doi:10.1210/jc.2008-2083)

Baumgartner R, Fernandez-Catalan C, Winoto A, Huber R, Engh RA \& Holak TA 1998 Structure of human cyclin-dependent kinase inhibitor p19INK4d: comparison to known ankyrin-repeat-containing structures and implications for the dysfunction of tumor suppressor p16INK4a. Structure 6 1279-1290. (doi:10.1016/S0969-2126(98)00128-2)

Costa-Guda J, Soong C-P, Parekh VI, Agarwal SK \& Arnold A 2013 Germline and somatic mutations in cyclin-dependent kinase inhibitor genes CDKN1A, CDKN2B, CDKN2C in sporadic parathyroid adenomas. Hormones \& Cancer 4 301-307. (doi:10.1007/s12672-013-0147-9)

Cromer MK, Starker LF, Choi M, Udelsman R, Nelson-Williams C, Lifton RP $\&$ Carling T 2012 Identification of somatic mutations in parathyroid tumors using whole-exome sequencing. Journal of Clinical Endocrinology and Metabolism 97 E1774-E1781. (doi:10.1210/jc.2012-1743)

Guo Y, Mahajan A, Yuan C, Joo SH, Weghorst CM, Tsai M-D \& Li J 2009 Comparisons of the conformational stability of the cyclin-dependent kinase (CDK) 4-interacting ankyrin repeat (AR) proteins. Biochemistry 48 4050-4062. (doi:10.1021/bi802247p)

Li J, Mahajan A \& Tsai MD 2006 Ankyrin repeat: a unique motif mediating protein-protein interactions. Biochemistry 45 15168-15178. (doi:10.1021/bi062188q)

Li J, Poi MJ \& Tsai MD 2011 Regulatory mechanisms of tumor suppressor P16(INK4A) and their relevance to cancer. Biochemistry 50 5566-5582. (doi:10.1021/bi200642e)

Marx SJ 2011 Hyperparathyroid genes: sequences reveal answers and questions. Endocrine Practice 17 (Suppl 3) 18-27. (doi:10.4158/EP11067.RA)

Newey PJ, Nesbit MA, Rimmer AJ, Attar M, Head RT, Christie PT, Gorvin CM, Stechman M, Gregory L, Mihai R et al. 2012 Whole-exome sequencing studies of nonhereditary (sporadic) parathyroid adenomas. Journal of Clinical Endocrinology and Metabolism 97 E1995-E2005. (doi:10.1210/ jc.2012-2303)

Pavletich NP 1999 Mechanisms of cyclin-dependent kinase regulation: structures of Cdks, their cyclin activators, and Cip and INK4 inhibitors. Journal of Molecular Biology 287 821-828. (doi:10.1006/jmbi.1999.2640)

Pellegata NS, Quintanilla-Martinez L, Siggelkow H, Samson E, Bink K, Hofler H, Fend F, Graw J \& Atkinson MJ 2006 Germ-line mutations in p27Kip1 cause a multiple endocrine neoplasia syndrome in rats and humans. PNAS 103 15558-15563. (doi:10.1073/pnas.0603877103)

Solomon DA, Kim JS, Jenkins S, Ressom H, Huang M, Coppa N, Mabanta L, Bigner D, Yan H, Jean W et al. 2008 Identification of p18 INK4c as a tumor suppressor gene in glioblastoma multiforme. Cancer Research $\mathbf{6 8}$ 2564-2569. (doi:10.1158/0008-5472.CAN-07-6388)

van Veelen W, Klompmaker R, Gloerich M, van Gasteren CJ, Kalkhoven E, Berger R, Lips CJ, Medema RH, Hoppener JW \& Acton DS 2009 P18 is a tumor suppressor gene involved in human medullary thyroid carcinoma and pheochromocytoma development. International Journal of Cancer 124 339-345. (doi:10.1002/ijc.23977)

Received in final form 9 October 2013

Accepted 11 October 2013

Made available online as an Accepted Preprint

14 October 2013 http://erc.endocrinology-journals.org DOI: 10.1530/ERC-13-0445
(C) 2013 Society for Endocrinology Printed in Great Britain
Published by Bioscientifica Ltd. 